\title{
The Four Strands
}

\author{
Paul Nation \\ Department of Linguistics, Victoria University of Wellington, Wellington, \\ New Zealand
}

The activities in a language course can be classified into the four strands of meaningfocused input, meaning-focused output, language-focused learning and fluency development. In a well designed course there should be an even balance of these strands with roughly equal amounts of time given to each strand. The research evidence for the strands draws on the input hypothesis and learning from extensive reading, the output hypothesis, research on form-focused instruction, and the development of speaking and reading fluency. The paper concludes with 10 principles based largely on the four strands. The strands framework and the principles provide a basis for managing innovation in language courses.

\section{doi: $10.2167 /$ illt039.0}

Keywords: four strands, curriculum, input, output, fluency

Innovation in language teaching needs to take account of research on language acquisition. One way of doing this is to make the innovation within a framework that fits with research findings. This paper describes a framework for looking at language courses to see if they provide an appropriate balance of opportunities for learning. The opportunities for learning language can be usefully divided into four strands: meaning-focused input, meaning-focused output, language-focused learning and fluency development. These are called strands because they can be seen as long continuous sets of learning conditions that run through the whole language course. Every activity in a language course fits into one of these strands. In a well balanced course roughly equal amounts of time can be given to each of the four strands. In the paper we will look at each of the four strands, their justification and how they can be put into practice. The paper concludes with a set of pedagogical principles based on the strands that can be used to guide the teaching of a language course.

\section{A Commonsense Justification of the Four Strands}

The basis of a commonsense approach to opportunities for learning is the time-on-task principle. How can you learn to do something if you don't do that during learning? How can you learn to read if you don't do reading? How can you learn to write without writing? The time-on-task principle simply says that the more time you spend doing something, the better you are likely to be at doing it. This is a very robust principle and there is no shortage of evidence, for example, that those who read a lot are better readers (Cunningham \& Stanovich, 1991) and that those who write a lot usually become better writers. 
However it is a simplistic principle and it can be rightfully criticised for ignoring the quality of the activity in favour of the quantity of the activity, and for not taking account of the ways in which language learning differs from other kinds of learning. Nevertheless, as one of a set of principles which do take account of these factors, the time-on-task principle is an important and essential one. Another idea underlying a commonsense approach is that there is something about each of the language skills of listening, speaking, reading and writing that makes them different from the others. It is thus necessary to give attention to each skill to make sure that these unique features are learned. It is also not difficult to argue that each of these four skills can be broken down even further, for example, that speaking monologue in a formal situation has unique features that differ from those involved in friendly conversation and so on. It is also possible to distinguish accuracy from fluency and thus see the necessity for giving fluency practice for each of the skills. There are thus commonsense justifications for including the four strands in a language course. Let us now see what each of these strands involves and some of the research evidence for them.

\section{Learning Through Listening and Reading}

The meaning-focused input strand involves learning through listening and reading - using language receptively. It is called 'meaning-focused' because in all the work done in this strand, the learners' main focus and interest should be on understanding, and gaining knowledge or enjoyment or both from what they listen to and read. Typical activities in this strand include extensive reading, shared reading, listening to stories, watching TV or films, and being a listener in a conversation.

This strand only exists if certain conditions are present.

(1) Most of what the learners are listening to or reading is already familiar to them.

(2) The learners are interested in the input and want to understand it.

(3) Only a small proportion of the language features are unknown to the learners. In terms of vocabulary, $95-98 \%$ of the running words should be within the learners' previous knowledge, and so only 5 or preferably only 1 or 2 words per hundred should be unknown to them ( $\mathrm{Hu} \&$ Nation, 2000).

(4) The learners can gain some knowledge of the unknown language items through context clues and background knowledge.

(5) There are large quantities of input.

If these conditions are not present, then the meaning-focused input strand does not exist in that course. Learning from meaning-focused input is fragile because there are usually only small gains with each meeting with a word, learning is dependent on the quality of reading and listening skills, and learning is affected by background knowledge. Because of this, large quantities of input are needed for this strand to work well. An extensive reading programme is one way of providing this quantity. 
Although many researchers criticise Krashen's (1985) input theory, none would disagree with the idea that meaningful comprehensible input is an important source of language learning. Among the best controlled studies of second language extensive reading is Waring and Takaki's (2003) study of vocabulary learning from a graded reader. This study showed that small amounts of learning of various strengths occurred incidentally as a result of meaning-focused reading. Elley and Mangubhai's (1981) classic study of the book flood showed a range of language learning benefits compared with a programme that was largely dominated by language-focused learning (or perhaps more accurately language-focused teaching).Compared with well planned deliberate learning, incidental learning gains from learning through input are small and are dependent on large quantities of input to gain sufficient repetition. Nation and Wang (1999) calculated that second language learners needed to read at least one graded reader every two weeks in order to get enough repetitions to establish substantial vocabulary growth. The gains from meaning-focused input however become substantial gains if there are large quantities of input.

\section{Learning Through Speaking and Writing}

The meaning-focused output strand involves learning through speaking and writing - using language productively. Typical activities in this strand include talking in conversations, giving a speech or lecture, writing a letter, writing a note to someone, keeping a diary, telling a story and telling someone how to do something.

The same kinds of conditions apply to meaning-focused output as apply to meaning-focused input.

(1) The learners write and talk about things that are largely familiar to them.

(2) The learners' main goal is to convey their message to someone else.

(3) Only a small proportion of the language they need to use is not familiar to them.

(4) The learners can use communication strategies, dictionaries or previous input to make up for gaps in their productive knowledge.

(5) There are plenty of opportunities to speak and write.

Many spoken activities will include a mixture of meaning-focused input and meaning-focused output. One person's output can be another person's input.

Swain's (1985) output hypothesis has been influential in clarifying the role of speaking and writing in second language learning. As its name suggests, the output hypothesis was initially formulated as a reaction to Krashen's (1985) input hypothesis and the inadequacy of the input hypothesis in explaining the effects of immersion education. 'Put most simply, the output hypothesis claims that the act of producing language (speaking and writing) constitutes, under certain circumstances, part of the process of second language learning' (Swain, 2005: 471). The opportunities that output provides for learning however are not exactly the same as those provided by input. Swain (1995) suggests three 
functions for output: (1) the noticing/triggering function, (2) the hypothesis testing function and (3) the metalinguistic (reflective) function.

The noticing/triggering function occurs when learners are attempting to produce the second language and they consciously notice that there are holes in their knowledge. That is, they do not know how to say what they want to say. Izumi's (2002) research indicates that the effect on acquisition of noticing a hole or gap through output was significantly greater than the effect of noticing through input. This effect can be explained by the conditions of productive as compared with receptive learning, and generative use as compared with retrieval. Productive learning involves having to search for and produce a word form, whereas receptive learning involves having to find a meaning for a word form. Productive learning typically results in more and stronger knowledge than receptive learning (Griffin \& Harley, 1996). Generative use involves meeting or using previously met language items in ways that they have not been used or met before and produces deeper learning than the simple retrieval of previously met items (Joe, 1998). Izumi (2002) suggests that the grammatical encoding that is required by output forces learners to integrate the new items into a more cohesive structure. Decoding items from input does not require this same kind of integration. That is, output sets up learning conditions that are qualitatively different from those of input. This is not to say that input is inferior, simply that it is different and thus an important part of a balanced set of opportunities for learning. The full effect of the noticing/ triggering function is not complete until learners have had the chance to make up for the lack that they have noticed. This can occur in several ways. (1) Having noticed a hole during output, the learners then notice items in input that they did not notice before. If learners notice that there is something they do not know when writing, they later 'read like a writer' giving attention to how others say what they wanted to say. This is often referred to as moving from semantic to syntactic processing. (2) Having noticed a hole during output, learners may successfully fill that gap through a lucky guess, trial and error, use of analogy, first language transfer or problem solving. Webb (2002) found that learners were able to demonstrate aspects of vocabulary knowledge of previously unknown words that they did not encounter during a learning task, but which they were able to work out through analogy and first language parallels. (3) Having noticed a hole during output, learners may deliberately seek to find the item by reference to outside sources like teachers, peers or dictionaries.

Swain's second function of output is the hypothesis-testing function. This involves the learner trying out something and then maintaining or modifying it on the basis of perceived success and feedback. This hypothesis-testing function is particularly important in interaction, but as in the case of writing this interaction need not be immediate. Negotiation can be a way of gaining comprehensible input and it can also be a way of modifying output (Pica et al., 1989). Elley (1989) found that an incidental focus on feedback on form by teachers during communicative classroom interaction resulted in significant learning. This learning can occur through getting corrective feedback, through successful modification of output and the achieving of successful unmodified 
communication. That is, as a result of output, hypotheses can be modified or confirmed.

The third function of output is the metalinguistic (reflective) function. This involves largely spoken output being used to solve language problems in collaboration with others. Common classroom applications of this idea include the use of activities like the strip story (Gibson, 1975) and dictogloss (Wajnryb, $1988,1989)$ where learners work together to construct or reconstruct a text. These activities involve a lot of talk about language and this talk can contribute to language learning (Swain \& Lapkin, 1998). The requirements of such activities are a deliberate reflective focus on language, typically within the context of language in use. Although this is made more likely by interaction, it is not limited to interaction. Other activities encouraging metalinguistic reflection include blackboard or group composition where learners cooperate to produce one piece of written work, and ask and answer (Simcock, 1993), where learners retell a text in an interview format. These activities combine meaning-focused output and language-focused learning because output becomes the means for deliberately focusing on language features.

\section{Language-focused Learning}

Language-focused learning has many names - focus on form, form-focused instruction, deliberate study and deliberate teaching, learning as opposed to acquisition, intentional learning and so on. It involves the deliberate learning of language features such as pronunciation, spelling, vocabulary, grammar and discourse. The term language-focused learning is preferred because terms like focus on form and form-focused instruction are misleading in that they can involve a deliberate focus on meaning as well as form, and need not involve instruction but can be the focus of individual autonomous learning. The ultimate aim of such learning is to deal with messages, but its short-term aim is to learn language items. Typical activities in this strand are pronunciation practice, using substitution tables and drills, learning vocabulary from word cards, intensive reading, translation, memorising dialogues and getting feedback about writing. The deliberate learning of strategies such as guessing from context or dictionary use is also included in this strand. Most of these language-focused learning activities can have a positive effect on learning and language use, but it is important that they are only a small part of the course and do not become the whole course. In total, the language-focused learning strand should not make up more than one-quarter of the time spent on the whole course.

Just as there are conditions for meaning-focused input and output, there are conditions for language-focused learning.

(1) The learners give deliberate attention to language features.

(2) The learners should process the language features in deep and thoughtful ways.

(3) There should be opportunities to give spaced, repeated attention to the same features. 
(4) The features that are focused on should be simple and not dependent on developmental knowledge that the learners do not have.

(5) Features that are studied in the language-focused learning strand should also occur often in the other three strands of the course.

Language-focused learning can have any of these effects.

It can add directly to implicit knowledge.

It can raise consciousness to help later learning.

It can focus on systematic aspects of the language.

It can be used to develop strategies.

Some activities in the language-focused learning strand, such as dictation, go in and out of fashion, but there is plenty of evidence, certainly in vocabulary learning, that deliberate learning can make a very useful contribution to a learner's language proficiency.

There has long been substantial evidence that deliberately learning vocabulary can result in large amounts of well retained useable knowledge (Nation, 2001: 296-316). There is evidence that deliberate learning is effective for the learning of multiword units (Boers et al., 2006). Williams (2005) provides a very clear and useful analysis of what might be required for effective deliberate learning of grammatical features (focus on form). There is plenty of evidence that such a focus has positive effects for language learning, but there is debate over whether this has to be within the context of an overall focus on communication or whether it can be fully decontextualised (Williams, 2005).

Evidence from vocabulary learning shows that very large amounts of learning can occur in limited amounts of learning time, although it is much more effective if the learning sessions are spaced further and further apart.

\section{Becoming Fluent in Listening, Speaking, Reading and Writing}

The fluency development strand should involve all the four skills of listening, speaking, reading and writing. In this strand, the learners are helped to make the best use of what they already know. Like meaning-focused input and output, the fluency development strand is also meaning-focused. That is, the learners' aim is to receive and convey messages. Typical activities include speed reading, skimming and scanning, repeated reading, 4/3/2, repeated retelling, ten-minute writing and listening to easy stories.

The fluency strand only exists if certain conditions are present.

(1) All of what the learners are listening to, reading, speaking or writing is largely familiar to them. That is, there are no unfamiliar language, or largely familiar content or discourse features.

(2) The learners' focus is on receiving or conveying meaning.

(3) There is some pressure or encouragement to perform at a faster than usual speed.

(4) There is a large amount of input or output. 
If the activity involves unknown vocabulary, it is not a fluency activity. If the focus is on language features, it is not a fluency activity. If there is no push to go faster, it is not a fluency activity. The fluency strand should make up about one-quarter of the course time. It is time out from learning new items and is a time for getting good at using what is already known.

Studies of fluency development in first language readers have found that fluency practice increases fluency and that assisted fluency activities seem to work better than unassisted activities (Kuhn \& Stahl, 2003). Studies of second language readers have also found an increase in fluency as a result of timed practice (Chung, forthcoming), and have found transfer between the first and second languages when language difficulty is controlled for (Bismoko \& Nation, 1974; West, 1961). Studies of the 4/3/2 technique, where the same talk is repeated to different listeners in a decreasing time frame (four minutes, then three minutes then two), have shown increases in fluency during the task, but surprisingly also increases in grammatical accuracy and grammatical complexity (Arevart \& Nation, 1991; Nation, 1989). Schmidt (1992) describes a range of theories to explain fluency development. What is common to many of these is that fluency development involves a change in the size of the language unit learners work with. Fluency, accuracy and complexity are most likely interdependent.

There are two major types of second language fluency activities, those that involve repetitive reception or production of the same material as in 4/3/2 and repeated reading, and those that do not as in easy extensive reading or the traditional speed reading course with passages and questions. For first language learners, Kuhn and Stahl (2003) found no advantage for one type of fluency practice over the other.

In the early stages of language learning especially, there is value in becoming fluent with a repertoire of useful sentences and phrases such as those listed in Crabbe and Nation's (1991) survival vocabulary. This fits with Palmer's (1925) fundamental guiding principle for the student of conversation - Memorize perfectly the largest number of common and useful word groups!. Palmer explains that 'perfectly' means to a high level of fluency. In most language courses not enough attention is given to fluency development, possibly because it does not involve the learning of new language items and thus is not seen as moving the learners forward in their knowledge of the language.

\section{Balancing the Four Strands}

Each strand should have roughly the same amount of time in a well balanced course that aims to cover both receptive and productive skills. The balancing of time needs to take account of what occurs inside the classroom and the language learning that occurs outside the classroom.

A teacher can check whether there is a good balance of the strands by noting the language activities that learners are involved in over two weeks or a month, classifying each of these into one or more of the four strands and noting how much time each one took. Ideally each strand should occupy about $25 \%$ of the course time. 
What justification is there for trying to have an equal amount of time for each strand? Ellis (2005) includes the following principles in his list of principles of instructed language learning.

Instruction needs to ensure that learners focus predominantly on meaning.

Instruction needs to ensure that learners also focus on form.

The three strands of meaning-focused input, meaning-focused output and fluency development are meaning-focused strands. They all involve activities where the learners' focus is on communicating and receiving messages. In the meaning-focused input and meaning-focused output strands, this meaningfocused communication pushes the boundaries of learners' knowledge and skill and results in the largely incidental learning of language features. In the fluency development strand, the messages are very easy and familiar ones but they are still the main focus of the activities. Thus three of the four strands, and thus three-quarters of the time, focus predominately on meaning, and one strand, the language-focused learning strand, focuses on form.

There is another justification for this three-to-one balance. Given the same amount of time, deliberate language-focused learning activities result in more learning than the incidental learning from meaning-focused activities. For example, the Waring and Takaki (2003) study showed that in approximately 56 minutes of meaning-focused reading of a graded reader, four words were learned reasonably well, and another twelve were partially learned. Studies of deliberate vocabulary learning when learners study word pairs $(2 \mathrm{~L}-1 \mathrm{~L})$ result in learning rates of around 35 words per hour, which are four or more times higher than the incidental rate (Nation, 2001: 298; Thorndike, 1908; Webb, 1962). This kind of comparison is not entirely fair however, because meaningfocused activities have a range of benefits for language learning, gaining content matter knowledge, skill improvement and enjoyment. Nonetheless, a major justification for language-focused learning is its focused efficiency. This focused efficiency needs to be balanced against the three less efficient but more widely beneficial meaning-focused strands.

In spite of these arguments, giving equal time to each strand is an arbitrary decision. It has been suggested that the time given to the strands could change as learners' proficiency develops. At the beginning stages there could be more language-focused learning and less fluency development. At the higher proficiency levels, fluency development could take a greater proportion of the time. I am not in favour of this as there are good arguments for developing fluency with items like numbers and useful multiword phrases right from the beginning of language learning. Similarly, learning more about the nature of language such as its history, etymology and pragmatic effects can be a useful support for learning at advanced levels.

\section{Integrating the Four Strands}

The four strands are opportunities for certain types of learning. They differ from each other according to the conditions that are needed for the different 
types of learning. They can fit together in many different ways. For example, in an intensive English programme with many different teachers, there may be different classes for spoken language (listening and speaking), reading, writing and language study. It would then be important to make sure that the spoken language classes, for example, not only had meaning-focused input and output activities, but also included fluency development activities and only a very small amount of language-focused learning. Adding up across the whole programme, there should be roughly equal amounts of each of the four strands.

In a content-based course that did not have a skill-based division of classes, the four strands could all occur within a unit of work. Language-focused learning could lead into meaning-focused input or output, and this could lead into a fluency activity on the same theme. Once again, a good teacher would be quickly checking to see if over a week or two there was a roughly equal amount of time given to each strand. Or language-focused learning could occur as it was needed in the context of meaning-focused work.

There are many ways of giving time to the four strands and these will depend on many factors like the skills and preferences of the teachers, the expectations of learners and the school, the time-tabling constraints, and current beliefs about language teaching and learning. What is important is that over a period of time each strand gets about the same amount of time.

\section{Principles and the Four Strands}

The following pedagogical principles are aimed at providing guidelines for teachers. They draw on an earlier larger list (Nation, 1993) and can usefully be compared with other lists of principles (Brown, 1993; Ellis, 2005; Krahnke \& Christison, 1983). The list is organised around the four strands, with the final two principles focusing on what should be covered in a course. Each principle is followed by a brief list of suggestions about how the principle could be put into practice.

(1) Provide and organise large amounts of comprehensible input through both listening and reading. This could involve providing an extensive reading programme, reading to the learners, getting learners to give talks for their classmates to listen to, arranging spoken communication activities and interaction via the internet.

(2) Boost learning through comprehensible input by adding a deliberate element. Note words on the board as they occur in listening, do consciousness raising activities before communicative tasks, get learners to reflect on new items they met while reading and explain problem items that come up in the context of communication activities.

(3) Support and push learners to produce spoken and written output in a variety of appropriate genres. Use communication activities in a range of situations, use role plays, match writing and speaking tasks to learner needs.

(4) Provide opportunities for cooperative interaction. Do group work involving split information, opinion gaps and information gaps, and get learners to work together on writing and reading. 
(5) Help learners deliberately learn language items and patterns, including sounds, spelling, vocabulary, multiword units, grammar and discourse. Do teacher-led intensive reading, give feedback on writing, deliberately teach language items and arrange individual study of language items.

(6) Train learners in strategies that will contribute to language learning. Work on guessing from context, dictionary use, word part analysis and learning using word cards.

(7) Provide fluency development activities in each of the four skills of listening, speaking, reading and writing. Run a speed reading course, include repeated reading, provide an extensive reading programme, do 4/3/2 activities, organise a regular ten-minute writing programme and do listening to stories.

(8) Provide a roughly equal balance of the four strands of meaning-focused input, meaning-focused output, language-focused learning and fluency development. Keep a record of the activities done in the course, the strand they fit into and the amount of time spent on them.

(9) Plan for the repeated coverage of the most useful language items. Focus on high frequency items, use controlled and simplified material and provide plenty of input at the same level.

(10) Use analysis, monitoring and assessment to help address learners' language and communication needs.

Within the constraints of the four strands and the principles described in this paper, it is possible to make innovative changes such as using computerassisted language learning, having a negotiated syllabus, making maximum use of the target language or taking an experience approach to learning. By following the guidelines described here, it is possible to ensure that innovation does not result in misbalanced courses and that innovation builds on what we know about language learning and teaching.

\section{Correspondence}

Any correspondence should be directed to Paul Nation, Department of Linguistics, Victoria University of Wellington, Wellington, New Zealand (Paul.Nation@vuw.ac.nz).

\section{References}

Arevart, S. and Nation, I.S.P. (1991) Fluency improvement in a second language. RELC Journal 22 (1), 84-94.

Bismoko, J. and Nation, I.S.P. (1974) English reading speed and the mother-tongue or national language. RELC Journal 5 (1), 86-89.

Boers, F., Eyckmans, J., Kappel, J., Stengers, H. and Demecheleer, M. (2006) Formulaic sequences and perceived oral proficiency: putting the Lexical Approach to the test. Language Teaching Research 10 (3), 245-261.

Brown, H.D. (1993) Requiem for methods. Journal of Intensive English Studies 7, 1-12.

Chung, M. (forthcoming) The effect of a speed reading course on reading fluency.

Crabbe, D. and Nation, I.S.P. (1991) A survival language learning syllabus for foreign travel. System 19 (3), 191-201. 
Cunningham, A.E. and Stanovich, K.E. (1991) Tracking the unique effects of print exposure in children: associations with vocabulary, general knowledge, and spelling. Journal of Educational Psychology 83 (2), 264-274.

Elley, W.B. and Mangubhai, F. (1981) The Impact of a Book Flood in Fiji Primary Schools. Wellington: New Zealand Council for Educational Research.

Elley, W.B. (1989) Vocabulary acquisition from listening to stories. Reading Research Quarterly 24 (2), 174-187.

Ellis, R. (2005) Principles of instructed language learning. System 33, 209-224.

Gibson, R.E. (1975) The strip story: a catalyst for communication. TESOL Quarterly 9 (2), $149-154$.

Griffin, G.F. and Harley, T.A. (1996) List learning of second language vocabulary. Applied Psycholinguistics 17, 443-460.

$\mathrm{Hu}, \mathrm{M}$. and Nation, I.S.P. (2000) Vocabulary density and reading comprehension. Reading in a Foreign Language 13 (1), 403-430.

Izumi, S. (2002) Output, input enhancement, and the noticing hypothesis: An experimental study on ESL relativization. Studies in Second Language Acquisition 24, $541-577$.

Joe, A. (1998) What effects do text-based tasks promoting generation have on incidental vocabulary acquisition? Applied Linguistics 19, 357-377.

Krahnke, K.J. and Christison, M.A. (1983) Recent language research and some language teaching principles. TESOL Quarterly 17 (4), 625-649.

Krashen, S. (1985) The Input Hypothesis: Issues and Implications. London: Longman.

Kuhn, M. and Stahl, S. (2003) Fluency: a review of developmental and remedial practices. Journal of Educational Psychology 95 (1), 3-21.

Nation, I.S.P. (1989) Improving speaking fluency. System 17 (3), 377-384.

Nation, I.S.P. (1993) Sixteen principles of language teaching. In L. Bauer and C. Franzen (eds) Of Pavlova, Poetry and Paradigms: Essays in Honour of Harry Orsman (pp. 209-224). Wellington: Victoria University Press.

Nation, I.S.P. (2001) Learning Vocabulary in Another Language. Cambridge: Cambridge University Press.

Nation, I.S.P. (in press) Teaching Vocabulary: Strategies and Techniques. Heinle Thomson.

Nation, P. and Wang, K. (1999) Graded readers and vocabulary. Reading in a Foreign Language 12 (2), 355-380.

Palmer, H. (1925) Conversation. In R.C. Smith (ed.) (1999) The Writings of Harold E. Palmer: An Overview (pp. 185-191). Tokyo: Hon-no-Tomosha.

Pica, T., Holliday, L., Lewis, N. and Morgenthaler, L. (1989) Comprehensible output as an outcome of linguistics demands on the learner. Studies in Second Language Acquisition 11, 63-90.

Schmidt, R. (1992) Psychological mechanisms underlying second language fluency. Studies in Second Language Acquisition 14, 357-385.

Simcock, M. (1993) Developing productive vocabulary using the 'Ask and answer' technique. Guidelines 15, 1-7.

Swain, M. (1985) Communicative competence: Some roles of comprehensible input and comprehensible output in its development. In S. Gass and C. Madden (eds) Input in Second Language Acquisition (pp. 235-253). Rowley, MA: Newbury House.

Swain, M. (1995) Three functions of output in second language learning. In G. Cook and B. Seidelhofer (eds) Principle and Practice in Applied Linguistics: Studies in Honour of H.G. Widdowson (pp. 125-144). Oxford: Oxford University Press.

Swain, M. (2005) The output hypothesis: Theory and research. In E. Hinkel (ed.) Handbook of Research in Second Language Teaching and Learning (pp. 471-483). Mahwah, NJ: Lawrence Erlbaum Associates.

Swain, M. and Lapkin, S. (1998) Interaction and second language learning: Two adolescent French immersion students working together. Modern Language Journal 82, 320-337.

Thorndike, E.L. (1908) Memory for paired associates. Psychological Review 15, 122-138.

Wajnryb, R. (1988) The Dicto-gloss method of language teaching: A text-based communicative approach to grammar. English Teaching Forum 26 (3), 35-38. 
Wajnryb, R. (1989) Dicto-gloss: A text-based communicative approach to teaching and learning grammar. English Teaching Forum 27 (4), 16-19.

Waring, R. and Takaki, M. (2003) At what rate do learners learn and retain new vocabulary from reading a graded reader? Reading in a Foreign Language 15 (2), $130-163$.

Webb, S. (2002) Investigating the effects of learning tasks on vocabulary knowledge. $\mathrm{PhD}$ thesis, Victoria University of Wellington.

Webb, W.B. (1962) The effects of prolonged learning on learning. Journal of Verbal Learning and Verbal Behavior 1, 173-182.

West, M. (1961) Letter in correspondence column on speed reading. ELT Journal 15 (3), $125-128$.

Williams, J. (2005) Form-focused instruction. In E. Hinkel (ed.) Handbook of Research in Second Language Teaching and Learning (pp. 671-691). Mahwah, N.J.: Lawrence Erlbaum Associates. 